\title{
DRYING METHOD EFFECTS ON THE ANTIOXIDANT ACTIVITY OF QUINCE (CYDONIA OBLONGA MILLER) TEA
}

\author{
Hamid Reza Gheisari ${ }^{凶}$, Khadijeh H. Abhari \\ Department of Food Hygiene, School of Veterinary Medicine, Shiraz University \\ 71345-1731 Shiraz, Iran
}

\begin{abstract}
Background. Quince has many health benefits. Dried quince has been used as a tea for centuries. The aim of this study was to investigate the influences of two drying methods on the antioxidant activity of the quince. Material and methods. Fifty two fresh Iranian quinces (Cydonia oblonga) were obtained from different parts of Shiraz. Half of the quinces were peeled and both peel and flesh immediately frozen at $-20^{\circ} \mathrm{C}$ individually. The remainder was divided in two groups, and dried with sun and oven drying methods. Proximate analysis, caloric, mineral and vitamin $\mathrm{C}$ contents were determined in the fresh quinces. The total phenolic, DPPH radical scavenging activity and reducing power analysis were done on flesh, peel, sun-dried and ovendried quinces.

Results. The proximate and nutritional composition of the fresh quinces was similar to those reported by other researchers. Oven-dried and quince peel contained higher amounts of phenolics than the sun-dried and flesh quinces, respectively. Sun-dried and flesh samples showed lower radical scavenging effect and reducing antioxidant capacity than oven-dried and quince peel, respectively.

Conclusion. Overall, oven drying can better preserve the antioxidative activity of the quince.
\end{abstract}

Key words: quince, antioxidative activity, drying, tea

\section{INTRODUCTION}

Free radicals and other reactive oxygen species are generated by exogenous chemicals or endogenous metabolic process in food systems or the human body. The radicals may cause oxidative damage by oxidizing biomolecules and results in cell death tissue damage. However, ingestion of antioxidative supplements, or foods containing antioxidants, may reduce the oxidative damage on the human body [Wang et al. 2006].

Several studies have shown that quince (Cydonia oblonga Miller) is a good and low-cost natural source of phenolic acids and flavonoids [Silva et al. 2004, 2008, Oliveira et al. 2007], which are potent antioxidants. The phenolic compounds are not evenly distributed in different tissues and the peel usually contains at least two times more phenolic compounds than the flesh. The peel also possesses the higher antioxidant activity and anti-proliferation activity against cancer cell lines [Sun et al. 2002].

These compounds could provide a chemical basis to some health benefits claimed for quince leaf and fruit in folk medicine, namely in haemorrhoids, bronchial asthma, and cough [Oliveira et al. 2007, 2008, Yildirim et al. 2001]. They also have been shown to inhibit the activity of tyrosine kinase, and decrease the risk of cardiovascular diseases by reducing the level of total cholesterol as well as low-density lipoprotein 
(LDL) cholesterol. Other health benefits include risk of osteoporosis in women [Ungar et al. 2003].

However, the supporting scientific information is lacking. At present, quince fruit is recognized as an important dietary source of health promoting compounds, due to its antioxidant, antimicrobial and antiulcerative properties [Fattouch et al. 2007, Fiorentino et al. 2006, 2007, García-Alonso et al. 2004, Hamauzu et al. 2005, 2006, Silva et al. 2004, 2008, Yildirim 2006, Wang et al. 2006]. Quince fruit (Cydonia oblonga Miller) is not appreciated fresh due to its pulp hardness, bitterness and astringency. But in the processed form, it is in high demand for consumption [Silva et al. 2002, 2005]. One of these processes is drying. Dehydration has become a widely used food preservation process allowing extension of the shelf-life of foods. The main objective of this process is the removal of water to the level at which microbial spoilage and deterioration reactions are minimized. Other advantages of drying are lower storage costs, higher concentration, and stability of active substances [Oliveira et al. 2006]. Today, the dehydrated food industry occupies an important place within general food industries throughout the world.

Dehydrating apples is nowadays a frequent practice, since dried apples are part of numerous prepared foods including snack preparations, integral breakfast foods, as well as others [Akpinar et al. 2003]. But little information is found about drying quince and the use of this fruit as a nutritious snack or a drink like tea. Different drying methods have been developed for preservation and they have their own characteristics. Drying by sun, hot air and oven-drying method are usually used. No information was found regarding the effects of different drying methods on antioxidant activities of Quince, therefore the aim of the present study was to detect antioxidant activity in Iranian cultivar of quince and investigate the influences of sun drying and oven drying on this characteristic.

\section{MATERIALS AND METHODS}

Fruit collection. Fifty two fresh Iranian quinces (Cydonia oblonga) were obtained from different parts of Shiraz. Half of the quinces were peeled and both the peel and flesh were immediately frozen at $-20^{\circ} \mathrm{C}$ individually. The remainder was divided in two groups, and dried using two methods. The analysis was done on 4 groups: 1. Flesh, 2. Peel, 3. Sun-dried quinces and 4. Oven-dried quinces.

Proximate analysis and caloric content of quince fruit. Moisture content, protein, ethereal extract, ash, and crude fibre were analyzed according to AOAC [2007] methods. Caloric content was calculated by application of the model established by Bognár and Piekarski [2000].

Mineral and vitamin $\mathbf{C}$ contents of quince fruit. Minerals constituents ( $\mathrm{Ca}, \mathrm{P}, \mathrm{Na}, \mathrm{K}, \mathrm{Mg}$ and $\mathrm{Fe}$ ) were determined according to AOAC [2007] methods: $\mathrm{Ca}$, $\mathrm{K}$ and $\mathrm{Fe}$ using an atomic absorption spectrophotometer (PERKN ELMER ${ }^{\circledR}$, Model 3100), and phosphorus (P) content was determined by the phosphomolybdate method. Vitamin $\mathrm{C}$ content was determined by application of the 2.6 dichloroindophenol volumetric method [AOAC 2007].

Drying processes. For each drying method, quinces were cut to small pieces. In sun-drying, quinces were put on clean trays and kept for $30 \mathrm{~h}$ in daylight (with the average temperature of $28^{\circ} \mathrm{C}$ ). In oven drying, quinces were placed in an oven at $50^{\circ} \mathrm{C}$ for $5 \mathrm{~h}$.

Extraction procedure. From all four groups, $10 \mathrm{~g}$ material was extracted with $100 \mathrm{ml}$ of $70 \%$ acetone by magnetic stirring at $20^{\circ} \mathrm{C}$ for 6 hours. The extracts were filtered through no. 1 Whatman paper on a vacuum-aided Buchner funnel and concentrated to dryness by rotary evaporation at $30^{\circ} \mathrm{C}$, under reduced pressure. The solid residue was dissolved in distilled water and lyophilized. The total extraction process was done in triplicate.

Measurement of total phenolics. The total phenolics in four groups were quantified by the method described by Makkar [2003]. Briefly, suitable aliquots of extracts were taken in a test tube and the volume was made to $0.5 \mathrm{ml}$ with distilled water followed by the addition of $0.25 \mathrm{ml}$ Folin-Ciocalteu $(1 \mathrm{~N})$ reagent and $1.25 \mathrm{ml}$ sodium carbonate solution $(20 \%)$. The tubes were vortexed and the absorbance was recorded at $725 \mathrm{~nm}$ (Model: UV-VIS 1700 Shimadzu, Japan) after $40 \mathrm{~min}$. The amount of total phenolics was calculated as tannic acid equivalent from the calibration curve using standard tannic acid solution $(0.1 \mathrm{mg} / \mathrm{ml})$.

DPPH radical scavenging activity. The scavenging activity of samples was measured in accordance with the method of Brand Williams [Brand-Williams et al. 1995]. The method was based on the reduction 
of methanolic DPPH' in the presence of a hydrogendonating antioxidant. $\mathrm{DPPH}{ }^{\circ}$ solution was an intense violet color and showed an absorption band at $515 \mathrm{~nm}$. Adsorption and color lowered when $\mathrm{DPPH}^{\circ}$ was reduced by an antioxidant compound. The remaining $\mathrm{DPPH}^{*}$ corresponded inversely to the radical-scavenging activity of the antioxidant. DPPH $(2 \mathrm{mg})$ was dissolved in $54 \mathrm{ml}$ of $\mathrm{MeOH}$. Aliquots of investigated extract $(50,100,200,500,1000,2000$ and $5000 \mu \mathrm{g})$ were dissolved in $1 \mathrm{ml}$ of $\mathrm{MeOH}$. Then $1.0 \mathrm{ml}$ of each solution was added to $1.0 \mathrm{ml}$ of $\mathrm{DPPH}^{*}$ solution at room temperature. The absorbance at $515 \mathrm{~nm}$ was measured against a blank $(1 \mathrm{ml} \mathrm{MeOH}$ in $1.0 \mathrm{ml}$ of DPPH' solution) using a UV-VIS1700 Shimadzu spectrophotometer. The results were expressed as percentage of reduction of the initial DPPH' adsorption by test samples: \% of reduction of the initial $\mathrm{DPPH}^{\circ}$ adsorption $=A_{\text {DPPH (t) }}-A_{\text {sample (t) }} / A_{\text {DPPH (t) }} \times 100, A_{\text {DPPH(t) }}$ is absorbance of DPPH' at time $t$ and $A_{\text {sample (t) }}$ is absorbance of sample at $t$ the same time.

Measurement of reducing power. The reducing power was quantified by the method described by Jayaprakashah et al. [2001]. The 50-250 $\mu \mathrm{g}$ phenolics from four groups was mixed with $2.5 \mathrm{ml}$ phosphate buffer $(200 \mu \mathrm{M}, \mathrm{pH}$ 6.6) and incubated with $2.5 \mathrm{ml}$ potassium ferricyanide $(1 \% \mathrm{w} / \mathrm{v})$ at $50^{\circ} \mathrm{C}$ for $20 \mathrm{~min}$. At the end of incubation, $2.5 \mathrm{ml}$ of $10 \%$ trichloroacetic acid solution was added and the samples were centrifuged at $9700 \mathrm{~g}$ for $10 \mathrm{~min}$. The supernatant $(2.5 \mathrm{ml})$ was mixed with $2.5 \mathrm{ml}$ distilled water and $0.5 \mathrm{ml}$ ferric chloride $(0.1 \% \mathrm{w} / \mathrm{v})$ solution. The absorbance was measured at $700 \mathrm{~nm}$ (Model: Model: UV-VIS1700 Shimadzu, Japan). Increase in absorbance of the reaction indicated the reducing power of the sample.

\section{STATISTICAL ANALYSIS}

Data of different characters in quince groups were summarized. Their means were compared using the one way ANOVA and Duncan's multiple range tests [SAS software, version 9.1]. $P<0.05$ was considered as a level of significance.

\section{RESULTS AND DISCUSSION}

Cydonia vulgaris Pers. (Cydonia oblonga Miller) is a small shrub belonging to the same family as apples and pears (Rosaceae). This species is the sole member of the genus. It is a small tree with bright golden yellow pome fruits, when mature. The fruit of $\mathrm{C}$. vulgaris, known as Quince, resembles an apple, but differs in having many seeds in each carpel. Pomes of Quince, have hard flesh of high flavour, but very acid, and these are largely used for marmalade, liqueur, jelly and preserves [Alesiani et al. 2010]. At present, quince fruit is recognized as an important dietary source of health promoting compounds, due to its antioxidant, antimicrobial and antiulcerative properties [Fattouch et al. 2007, Hamauzu et al. 2005, 2006, Silva et al. 2004, 2008].

Tea is one of the most widely consumed beverages in the world, and can be grouped into three types, including black tea, oolong tea and green tea as a result of manipulations of the leaf. For centuries, humans have enjoyed the antioxidant effects of home brewed tea, even if they had no knowledge of antioxidants. Tea tastes good, and it provides a certain comfort by potentially protecting one from cancers. It also contains caffeine, which has stimulating effects on the heart. Drinking tea may produce side effects such as drug interactions, brittle bones, teeth discoloration, sleeping disturbances, constipation, and headaches. Therefore, using a natural alternative such as dried quince has been long considered. Drying methods may affect the useful characteristics of the fruit such as antioxidative efficacy.

The proximate and nutritional composition of fresh quinces are shown in Table 1. They are similar to those reported by other researchers [Sharma et al. 2011, Silva et al. 2005, Rodriguez-Guisado et al. 2009]. Moisture contents of flesh, peeled, sun-dried and oven-dried quinces were $76.44 \pm 0.15,80.71 \pm 0.26$, $5.46 \pm 0.09$ and $4.23 \pm 0.11$, respectively. Total phenolic content in flesh, peel, sun-dried and oven-dried samples were $7.16 \pm 0.84,19.45 \pm 1.26,10.39 \pm 1.04$ and $36.72 \pm 3.57 \mathrm{mg}$ tannic acid/g of sample, respectively. As can be seen, oven-dried and quince peel contained higher amounts of phenolics than sun-dried and flesh quinces, respectively.

Among the phytochemicals, phenols, have received a great deal of attention because of their antioxidant activity [Tsuda et al. 1994]. Phenolic compounds tend to accumulate in the dermal tissues of plant bodies because of their potential roles in protection against ultraviolet radiation, to act as attractants 
Table 1. Proximate and nutritional composition of fresh quince (mean $\pm \mathrm{SD})$

\begin{tabular}{lr}
\hline \multicolumn{1}{c}{ Parameter } & \multicolumn{1}{c}{ Value } \\
\hline Moisture, \% & $78.86 \pm 1.19$ \\
Ether extract, \% & $0.11 \pm 0.04$ \\
Protein, \% & $0.43 \pm 0.15$ \\
Ash, \% & $2.45 \pm 0.08$ \\
Crude fiber, \% & $1.80 \pm 0.26$ \\
Carbohydrate, \% & $15.40 \pm 1.18$ \\
Calcium, mg/100 g & $8.25 \pm 0.14$ \\
Phosphorus, $\mathrm{mg} / 100 \mathrm{~g}$ & $16.83 \pm 0.39$ \\
Potassium, mg/100 g & $195.62 \pm 2.86$ \\
Iron, mg/100 g & $0.74 \pm 0.02$ \\
Vitamin C, mg/100 g & $15.12 \pm 0.78$ \\
Energy, Kcal & $56.07 \pm 0.45$ \\
\hline
\end{tabular}

in fruit dispersal, and as defense chemicals against pathogens and predators [Liu et al. 2005].

Drogoudi et al. [2008] reported a positive correlation between total antioxidant activity and total phenolic content in apple flesh and peel $(r=0.914$ and 0.977 , respectively). Apple peel contained from 1.5 to 9.2 times greater total antioxidant activity and from 1.2 to 3.3 times greater total phenolic content compared with flesh.

In the study of Magalhães et al. [2009] total phenolics content decreased in the following order: peel $>$ pulp $>>$ seed $(6.3,2.5$ and $0.4 \mathrm{~g} / \mathrm{kg}$ of methanolic extract, respectively). Although total phenolic content of pulp and peel extracts were different ( 2.5 and $6.3 \mathrm{~g} / \mathrm{kg}$ of methanolic extract, respectively), total caffeoylquinic acids content was closer (2.5 and $3.2 \mathrm{~g} / \mathrm{kg}$ of methanolic extract, respectively). They suggested, like Silva et al. [2004 and 2008], that caffeic acid derivatives seem to be the main cause for the antioxidant activity of quince fruit. In fact, their results indicate that the antioxidant activity of quince pulp, peel and seed methanolic extracts is statistically correlated with total phenolic content $(r=0.913 ; p<0.05)$ and especially with total caffeoylquinic acids content $(r=0.989 ; p<0.05)$.
Figure 1 shows the concentrations required to scavenge DPPH radical and the scavenging values as inhibition (50 per cent). Sun-dried and flesh showed lower radical scavenging effect than oven-dried and quince peel, respectively. In the DPPH assay, the higher the antioxidant activity the lower the IC50.

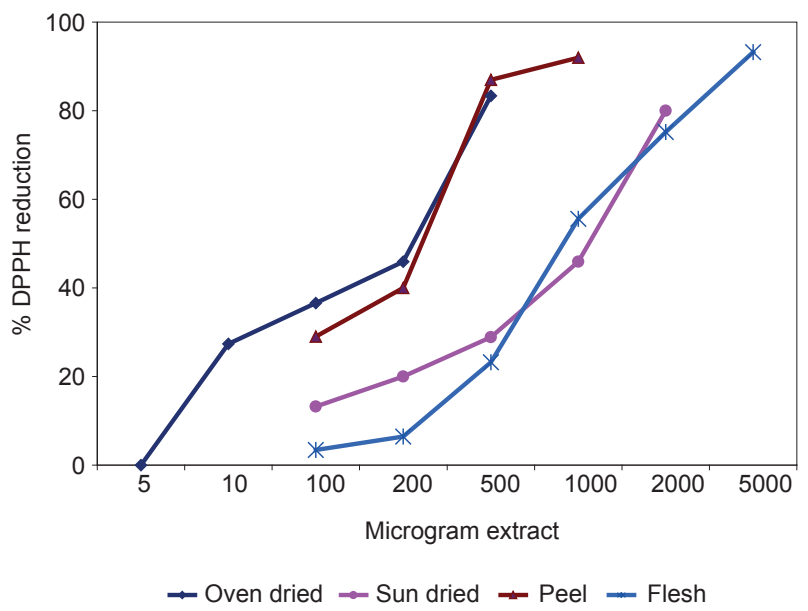

Fig. 1. Free radical scavenging activities of different quince samples

When DPPH radical scavenging capacity was tested, a linear increase of activity was observed with the tested amount of sample. Reductions equal to $83.35 \%$, $28.91 \%, 87 \%$ and $23.20 \%$ were obtained for $0.5 \mathrm{mg}$ of oven-dried, sun-dried, peel and flesh extracts, respectively.

The study of Kondo et al. [2002] demonstrates that the free radical scavenging activity in apple skin and flesh may depend on the concentration and composition of polyphenolics.

A concentration dependent increase in reducing power was observed (Fig. 2). The overall trend of reducing antioxidant capacity followed the concentrations of total phenolics. Therefore, oven-dried had the highest reducing power and flesh showed the lowest.

Although the peel has substantially higher phytochemical content and greater antioxidant activity, followed by peel + flesh (whole fruit) and apple pulp, the real bioactive 'yield' also depends on tissue weight classification of the richest phytochemical-containing part of the fruit. Because peel makes up only a very small 


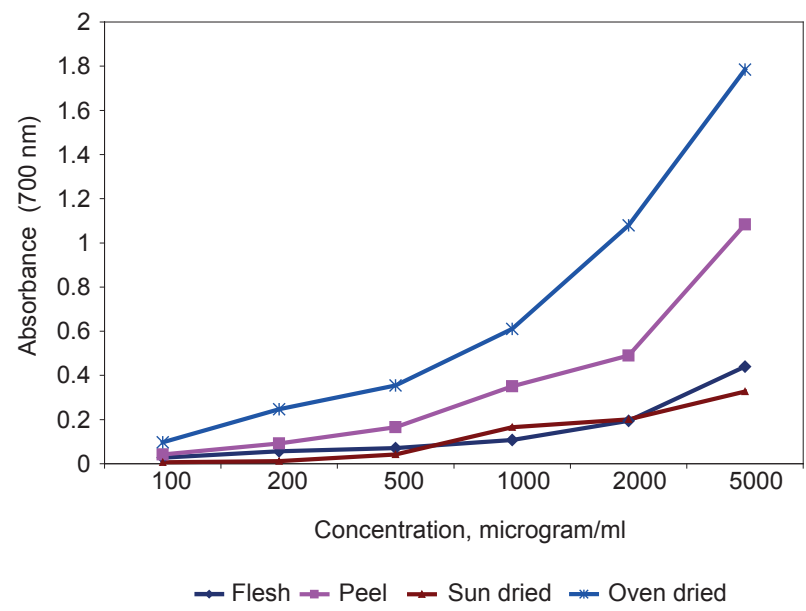

Fig. 2. Antioxidant activity of different quince samples

percentage of the whole fruit weight, its significance to the consumer is disputable [Veberic et al. 2005].

Sultana et al. [2012] studied the effect of drying techniques (ambient-drying and oven-drying) on the total phenolic contents and antioxidant activity of selected fruits (apple (Malus pumila, var. skysuper), plum (Prunus salicina, var. Fezele manani), apricot (Prunus armeniaca L. var. Nuri), strawberry (Fragaria ananassa var. Corona) and mulberry (Morus alba L. var. serrata) were studied. The results of their study revealed that the amounts of total phenolic and antioxidant activity of all the tested fruits, except those of apricot, decreased after drying treatment; relatively more pronounced decline was observed for the ambient dried samples as against oven-drying.

In conclusion, the results of this study indicate that oven-dried quince exhibit strong antioxidant activities. The scavenging activities observed against DPPH and peroxyl radicals lead us to propose oven-dried quince as a promising natural source of antioxidants suitable for application in nutritional/pharmaceutical fields, in the prevention of free radical-mediated diseases. Further studies are needed to explore the potential of quince tea bioactive compounds as chemopreventive and therapeutic agents.

\section{REFERENCES}

Akpinar E.K., Bicer Y., Yildiz C., 2003. Thin layer drying of red pepper. J. Food Eng. 59, 1, 99-104.
Alesiani D., Canini A., D’Abrosca B., DellaGreca M., Fiorentino A., Mastellone C., Monaco P., Pacifico S., 2010. Antioxidant and antiproliferative activities of phytochemicals from Quince (Cydonia vulgaris) peels. Food Chem. 118, 199-207.

AOAC. 2007. Official Methods of Analysis. Association of Official Analytical Chemists Arlington, VA.

AOAC. 2010. Official Methods of Analysis. Association of Official Analytical Chemists Arlington, VA.

Bognár A., Piekarski J., 2000. Guidelines for recipe information and calculation of nutrient composition of prepared foods (Dishes). J. Food Comp. Anal. 13, 391-410.

Brand-Williams W., Cuvelier M.E., Berset C., 1995. Use of free radical method to evaluate antioxidant activity. Lebensm. Wiss. Technol. 28, 25-30.

Drogoudi P.D., Michailidis Z., Pantelidis G., 2008. Peel and flesh antioxidant content and harvest quality characteristics of seven apple cultivars. Sci. Hortic. 115, 149-153.

Fattouch S., Caboni P., Coroneo V., Tuberoso C.I.G., Angioni A., Dessi S., Marzouki N., Cabras P., 2007. Antimicrobial activity of tunisian quince (Cydonia oblonga Miller) pulp and peel polyphenolic extracts. J. Agric. Food Chem. 55, 963-969.

Fiorentino A., D’Abrosca B., Pacifico S., Mastellone C., Piscopo V., Monaco P., 2006. Spectroscopic identification and antioxidant activity of glucosylated carotenoid metabolites from Cydonia vulgaris fruits. J. Agric. Food Chem. 54, 9592-9597.

Fiorentino A., D’Abrosca B., Pacifico S., Mastellone C., Piccolella S., Monaco P., 2007. Isolation, structure elucidation, and evaluation of cydonioside $\mathrm{A}$, an unusual terpenoid from the fruits of Cydonia vulgaris. Chem. Biodiver. 4, 973-979.

García-Alonso M., Pascual-Teresa S., Santos-Buelga C., Rivas-Gonzalo J.C., 2004. Evaluation of the antioxidant properties of fruits. Food Chem. 84, 13-18.

Hamauzu Y., Hisako Y., Takaroni I., Kume C., Omanyuda M., 2005. Phenolic profile, antioxidant property, and anti-influenza viral activity of chinese quince (Pseudocydonia sinensis Schneid.), quince (Cydonia oblonga Mill.) and apple (Mallus domestica Mill.) fruits. J. Agric. Food Chem. 53, 928-934.

Hamauzu Y., Takaroni I., Kume C., Irie M., Hiramatsu K., 2006. Antioxidant and antiulcerative properties of phenolics from Chinese quince, quince, and apple fruits. J. Agric. Food Chem. 54, 765-772.

Jayaprakasha G.K., Singh R.P., Sakariah K.K., 2001. Antioxidant activity of grape seed (Vitis vinifera) extracts on peroxidation models in-vitro. Food Chem. 73, 285-290. 
Kondo S., Tsuda K., Muto N., Ueda J., 2002. Antioxidative activity of apple skin or flesh extracts associated with fruit development on selected apple cultivars. Sci. Hortic. 96, 177-185.

Liu R.H., Liu J., Chen B., 2005. Apples prevent mammary tumors in rats. J. Agric. Food Chem. 53, 6, 2341-2343.

Magalhães A.S., Silva B.M., Pereira J.A., Andrade P.B., Valentão P., Carvalho M., 2009. Protective effect of quince (Cydonia oblonga Miller) fruit against oxidative hemolysis of human erythrocytes. Food Chem. Toxic. 47, 1372-1377.

Makkar H.P.S., 2003. Quantification of tannins in tree and shrub foliage: A laboratory manual. Kluwer Acad. Publ. Dordrecht, The Netherlands.

Oliveira W.P., Bott R.B., Souza C.R.F., 2006. Manufacture of standardized dried extracts from medicinal Brazilian plants. Drying Technol. 24, 4, 523-533.

Oliveira A.P., Pereira J.A., Andrade P.B., Valentão P., Seabra R.M., Silva B.M., 2007. Phenolic profile of Cydonia oblonga Miller leaf. J. Agric. Food Chem. 55, 7926-7930.

Oliveira A.P., Pereira J.A., Andrade P.B., Valentão P., Seabra R.M., Silva B.M., 2008. Organic acids composition of Cydonia oblonga Miller leaf. Food Chem. 111, 393-399.

Rodriguez-Guisado I., Hernandez F., Melgarejo P., Legua P., Martinez R., Martinez J.J., 2009. Chemical, morphological and organo leptical characterisation of five Spanish quince tree clones (Cydonia oblonga Miller). Sci. Hortic. 122, 491-496.

Sharma R., Joshi V.K., Rana J.C., 2011. Nutritional composition and processed products of Quince (Cydonia oblonga Mill.). Ind. J. Nat. Prod. Res. 2, 3, 354-357.

Silva B.M., Andrade P.B., Ferreres F., Domingues A.L., Seabra R.M., Ferreira M.A., 2002. Phenolic profile of quince fruit (Cydonia oblonga Miller) (pulp and peel). J. Agric. Food Chem. 50, 4615-4618.

Silva B.M., Andrade P.B., Valentão P., Ferreres F., Seabra R.M., Ferreira M.A., 2004. Quince (Cydonia oblonga
Miller) fruit (pulp, peel, and seed) and jam: antioxidant activity. J. Agric. Food Chem. 52, 4405-4712.

Silva B.M., Andrade P.B., Martins R.C., Valentao P., Ferreres F., Seabra R.M., Ferreira M.A., 2005. Quince (Cydonia oblonga Miller) fruit characterization using principal component analysis. J. Agric. Food Chem. 53, 111-122.

Silva B.M., Valentão P., Seabra R.M., Andrade P.B., 2008. Quince (Cydonia oblonga Miller): an interesting dietary source of bioactive compounds. In: Food chemistry research developments. Ed. K.N. Papadopoulos. Nova Sci. Publ. New York, 243-266.

Sultana B., Anwar F., Ashraf M., Saari N., 2012. Effect of drying techniques on the total phenolic contents and antioxidant activity of selected fruits. J. Med. Plants Res. 6, 161-167.

Sun J., Chu Y.F., Wu X., Liu R.H., 2002. Antioxidant and antiproliferative activities of common fruits. J. Agric. Food Chem. 50, 7449-7454.

Tsuda T., Watanabe M., Oshima K., Norinobu S., Choi S.W., Kawakishi S., Osawa T., 1994. Antioxidative activity of anthocyanin pigments cyanidin 3-O-b-D-glucoside and cyanidin. J. Agric. Food Chem. 42, 11, 2407-2410.

Ungar Y., Osundahunsi O.F., Shimoni E., 2003. Thermal stability of genistein and daidzein and its effect on their antioxidant activity. J. Agric. Food Chem. 51, 4394-4399.

Veberic R., Trobec M., Herbinger K., Hofer M., Grill D., Stampar F., 2005. Phenolic compounds in some apple (Malus domestica Borkh) cultivars of organic and integrated production. J. Sci. Food Agric. 85, 1687-1694.

Wang X., Jia W., Zhao A., Wang X., 2006. Anti-influenza agents from plants and traditional Chinese medicine. Phytother. Res. 20, 335-341.

Yildirim H.T., 2006. Evaluation of colour parameters and antioxidant activities of fruit wines. Int. J. Food Sci. Nutr. 57, 47-63.

Yildirim H.T., Oktay M., Bilaloglu V., 2001. Antioxidant activity of the leaf of Cydonia vulgaris. Turkish J. Med. Sci. 21, 23-27.

Accepted for print - Zaakceptowano do druku: 11.11.2013 